\title{
Design and Construction of a 3-Phase Induction Motor Wireless Control System
}

\author{
Daniel Kumi Owusu ${ }^{1}$, Christian Kwaku Amuzuvi ${ }^{2, ~ * ~}$ \\ ${ }^{1}$ Department of Electrical and Electronic Engineering, Takoradi Technical University, Takoradi, Ghana \\ ${ }^{2}$ Department of Renewable Energy Engineering, University of Mines and Technology, Tarkwa, Ghana
}

Email address:

daniel.owusu.kumi@tpoly.edu.gh (D. K. Owusu), ckamuzuvi@umat.edu.gh (C. K. Amuzuvi)

${ }^{*}$ Corresponding author

\section{To cite this article:}

Daniel Kumi Owusu, Christian Kwaku Amuzuvi. Design and Construction of a 3-Phase Induction Motor Wireless Control System. Journal of Electrical and Electronic Engineering. Vol. 8, No. 3, 2020, pp. 92-102. doi: 10.11648/j.jeee.20200803.13

Received: June 20, 2020; Accepted: July 7, 2020; Published: July 17, 2020

\begin{abstract}
Infrared (IR) wireless transmission technology has proven to be reliable in electric motor control. The existing control schemes for electric motors require the operator to be at the location of the motors or resort to the use of wired controls. Wired motor controls can fail due to objects falling on them and accidental disconnections. Also, voltage drops in the control wires are wasted in generating heat and increase the cost of electricity tariffs. Further, there is increase in labour cost and installation of wired motor control. Additionally, there are slips, trips and fall hazards associated with control trailing wires. In this research, a wireless control system for a three-phase, $415 \mathrm{~V}, 50 \mathrm{~Hz}$, squirrel-cage induction motor is designed, simulated and implemented. The issues of voltage drop in control wires is minimised because of the reduced wires involved with this control scheme, thereby improving on the motor efficiency. The transmitter transmits IR signal to the receiver. There is a phototransistor in the receiver that receives the IR signal, amplifies it and decodes it with the help of a microcontroller. The output from the microcontroller is used to regulate auto-transformers to control the three-phase voltage to the motor. The designed system can wirelessly start, stop and change the speeds of induction motor for three successive speed levels. The receiver senses signal from the transmitter within a distance of $9 \mathrm{~m}$. The system is designed to switch the motor into standby mode and then proceed to speeds one, two, three and then finally stop the motor. The developed infrared-based wireless transceiver can be adopted to control a three-phase, $415 \mathrm{~V}, 50 \mathrm{~Hz}$, squirrel-cage induction motor at remote and inaccessible areas such as water treatment and three-phase separation plants.
\end{abstract}

Keywords: Infrared Wireless Transmission, Transmitter, Receiver, Induction Motor

\section{Introduction}

The traditional methods of starting induction motors are direct-on-line starter, forward and reverse starter, star-delta starter, auto-transformer starter, and solid-state soft starter [1]. The conventional control methods of induction motors include: changing of the applied voltage, rotor resistance control, cascade control, pole changing schemes, stator voltage control, and vector control.

The main difference between a motor starter, and a motor controller is that, motor controllers do not provide overload protection, whilst motor starters provide protection for overload conditions of motors [2]. Control and starting methods are implemented on site or remotely using wires for connection.

Wired control, attracts extra financial cost with respect to the required lengths of wires to cover the distance between the location of the motor and the control system, with the associated accessories to set it up. Motor control circuits are designed to perform a variety of functions; including: starting, stopping, reversing, and speed control [3. 4]. There are several different control methods, both wired, and wireless, that are used to control three-phase induction motors. Related works on motor controls are reviewed to appreciate the need to use infrared wireless transmission technology. The aim for the development of an infrared-based wireless transceiver to control a three-phase, $415 \mathrm{~V}, 50 \mathrm{~Hz}$, squirrel-cage induction motor at remote and inaccessible areas was achieved in this research work. 


\subsection{Induction Motors}

3-ph, $415 \mathrm{~V}, 50 \mathrm{~Hz}$ squirrel-cage induction motors are also called asynchronous motors. These are the most common among the three-phase motors used for industrial applications because of their simple, rugged construction and efficiency. Almost $90 \%$ of alternating current (ac) motors that are used in the industries are induction motors [5].

\subsubsection{Three-Phase Squirrel-Cage Induction Motors}

The squirrel-cage motor derives its name from the shape in which its rotor is designed. The rotor of a squirrel-cage induction motor is made up of heavy copper bars which are joined together at each end by end rings, usually made of copper or brass [6]. These types of induction motors require three-phase supply for operation.

\subsubsection{Single-Phase Induction Motors}

Single-phase induction motors are inferior in performance and larger in weight and volume as compared to three-phase motors of the same rating [7]. The single-phase induction motors use single-phase ac supply for operation. A single-phase stator has two windings sited at an angle of $90^{\circ}$ to each other. One of these windings is known as the main winding, while the other is called the auxiliary winding or starting winding.

Single-phase induction motors are often known by the names of the starting methods [8]. These include Capacitor Start Induction Run (CSIR), Capacitor Start Capacitor Run (CSCR), Resistance Start Induction Run (RSIR) and Permanent-Split Capacitor (PSC) motors.

\subsection{Starting Methods of Three-Phase Induction Motors}

Three-phase induction motors are self-starting [9]. Therefore, three-phase induction motors employ starting methods because of the following reasons: i) to reduce heavy starting currents and prevent motor from overheating; and ii) provide overload and no-voltage protection.

In motor starter circuits, there are power circuits and control circuits. The power circuit is where the main supply flows through to the motor, whilst the control circuit is usually the part of the main supply that is used to power the control components. The basic components that are used in the design of motor starters include; cables, circuit breakers, fuses, start, stop and emergency stop pushbutton switches, contactors, thermal overload relays and connectors. The indication components such as indicating lights, buzzers, etc. can be added. The control circuit power is usually lower than the rated voltage and it can also be ac or dc.

\subsection{Wireless Communication}

Wireless communication is the exchange of electrical signals (information) from sources to destinations, without the use of any physical conductors [10]. The first wireless communication was done over line-of-sight distances by using smoke signals, torch signaling, flashing mirrors, signal flares or semaphore flags. Surveillance stations were built on hill tops and along roads to relay these messages over long distances. Marconi established the first wireless transmission in 1895 from the Isle of Wight 18 miles away to a tugboat after the invention of the telephone [11]. Ever since, advancements have been made in wireless communication. Transmission of wireless signal can be either analogue or digital or combination of both. The usage of wireless technology has made information transfer faster and easier as compared to wired technology of information transfer. Wireless technology is used in medicine (e-health), security, media, telecommunication, remote control, entertainment, marine services, etc.

\subsubsection{The Wireless Spectrum}

The electromagnetic spectrum is a chart of all the types of identified frequencies of electromagnetic radiations. Electromagnetic radiations are the radiant energies released by certain electromagnetic methods. It splits all the types of the lights, based on wavelengths, frequencies and their corresponding energy levels.

\subsubsection{Methods of Spectrum Allocation}

The methods of spectrum allocation are defined and assigned by procedures to service operators [12]. Every country has a mandated institution that is responsible for spectrum allocation. The regulating body established by law in Ghana is the National Communications Authority (NCA). The NCA was established by the National Communications Act 1996 Act 524, now repealed and replaced by the National Communications Authority Act of 2008, Act 769 to regulate communications by wire, cable, radio, television, satellite and similar means of technology for the orderly development and operation of efficient communications services in Ghana [13]. The need to manage a country's spectrum is to balance societal needs, ensure efficient use, promote innovation and ensure fair competition among operators. Among the notable methods for spectrum allocation are first-come-first-served, beauty contest, lottery and auction.

\subsubsection{Wireless Communication Standards}

Standardisation is needed for interaction between communication systems. There are various national organisations and international organisations that decide on Standards [14]. The NCA is responsible for setting the communications standards in Ghana. The Institute of Electrical and Electronics Engineers Standards Association (IEEE-SA) is an organisation under the Institute of Electrical and Electronics Engineers (IEEE), that generates worldwide standards in broad range of electrical and electronic engineering [15]. The International Telecommunication Union (ITU) is the standardisation body under IEEE-SA, that develops and coordinates wireless communication standards. The ITU has different organisations that represent the various continents [16]. The organisation responsible for Africa is African Telecommunications Union (ATU). All these groups undergo extensive procedures for standards development that involves input from interested parties and companies. 


\subsection{Wireless Systems}

Wireless systems are collections of subsystems, that operate interdependently and use unguided electromagnetic wave propagation to perform some specified functions. Some of the wireless systems are detailed in this section.

\subsubsection{Cellular Telephone Systems}

Cellular telephone systems provide two-way voice and data communication within regional, national or international reception. The cellular telephone system is a technology that substitutes a single high-power transmitter with a large number of low-power transmitters for communication between any two devices over a large geographical area [17]. The main goal of this technology is to offer communication between moving telephone sets over a wide area, known as mobile stations or between one mobile unit and a fixed unit, known as land-line unit. The cellular telephone system uses a huge number of low-power wireless transmitters to build cells to house huge numbers of subscribers in a large area [18]. The schematic diagram of a cellular telephone system is depicted in Figure 1 [19].

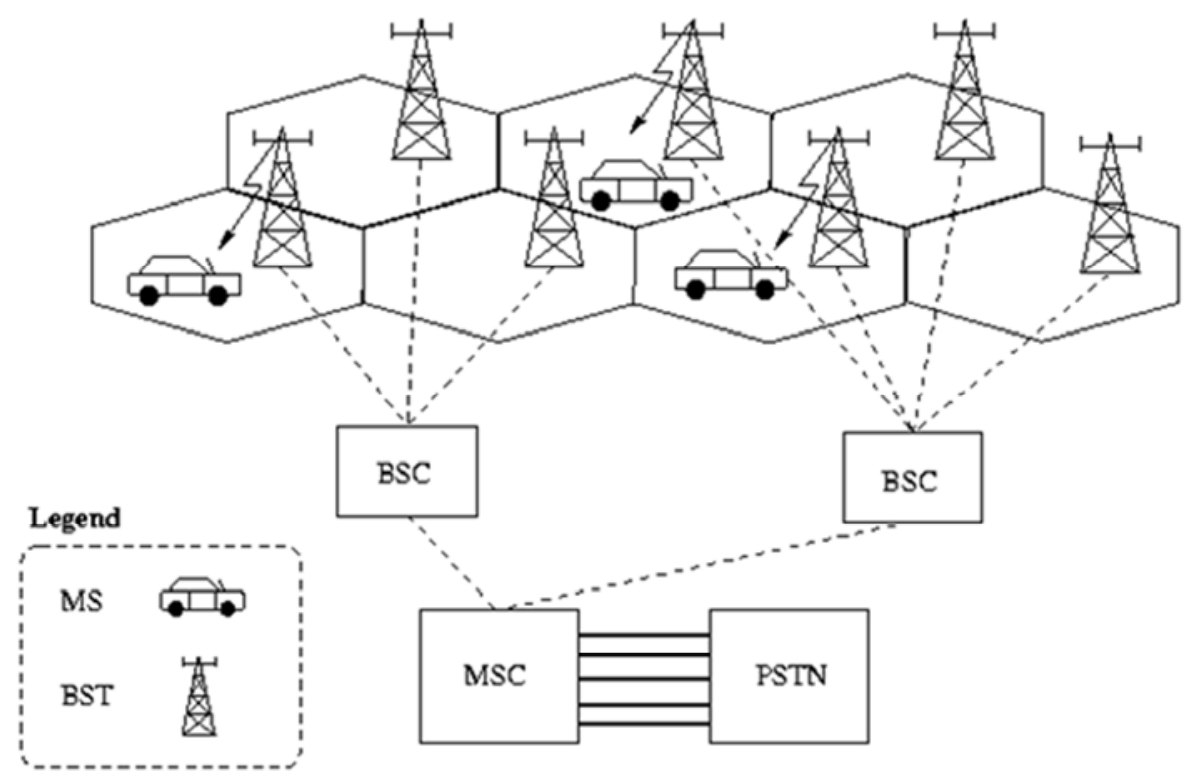

Figure 1. Schematic Diagram of a Cellular Telephone System.

\subsubsection{Wireless Local Area Networks}

With Wireless Local Area Networks (WLANs), mobile users wirelessly connect to two or multiple devices. It gives users freedom to move around within its range to be connected to the network. WLANs are usually located within areas such as campuses, hospitals, offices and homes. This technology is based on IEEE 802.11 standard [20]. WLANs transmission range frequency is within $2.4 \mathrm{GHz}$ band. It does not need line-of-sight for transmission or connection between devices. Wireless access points (base stations) are linked to an ethernet hub or a serve and transmit a radio frequency over its coverage area, that can penetrate through walls and non-metal barriers [21].

The modem varies one or more properties of the periodic waveform (carrier signal) with a modulating signal, that contains the information for transmission. It also extracts the original information from a modulated carrier wave. The router forwards information (signal) between the various components of the network. These switches direct incoming data from any of multiple input ports to the precise output port, that will take the data toward its proposed end [22]. The server stores, retrieves, and sends computer files and data to other computers on a network. The Wi-Fi provides wireless access point.

\subsubsection{Wide Area Wireless Data Services}

With this method, different areas of WLANs or cells are connected wirelessly to provide service to a large geographic area. Such services are usually provided for smart phones and other handheld devices sold by the same cellular service providers, and their retail partners [23]. However, other mobile devices can use them as well [24].

\subsubsection{Broadband Wireless Access}

This is high speed internet and data provided through WLANs. It is either fixed or mobile. This can provide a high-speed wireless fixed connectivity to locations such as hospitals, homes, laboratory, and offices [25]. Local Multipoint Distribution System (LMDS) and Multichannel Multipoint Distribution Service (MMDS) are some of the fixed wireless broadband technologies for broadband microwave wireless transmission, direct from a specific antenna to homes and businesses by a line-of-sight range [26]. The technology is similar to Digital Subscriber Line (DSL) and cable modem, but the mode of transmission is wireless [27].

\subsubsection{Paging Systems}

A paging system permits senders to send information (signal) to people within the same system coverage areas. This technology is a unidirectional (one-way) communication system. Information transmission is done by telephone system or a dispatch message centre. Paging is less expensive than other mobile communications systems because it was and still 
is primarily a one-way system [28]. The information is in the form of a display page, a tone only page or a voice page. For paging message, the user address (cap code) and the actual information are needed [29].

\subsubsection{Satellite Networks}

This is a wireless system, in which the outgoing (upstream) and the incoming (downstream) information are sent from a transmitter and arrives at a receiver through a satellite. Satellite network is used to create a communication channel between a source transmitter and receivers at different locations on earth as depicted in Figure 2 [30].

A review of related works on the control of three-phase induction motors discovered a number of procedures, such as: multilevel control [31, 32]; variable frequency control [33, 34]; direct torque control [35]; fuzzy logic control [36]; sensorless control [37]; sensor-based control [38]; and other available control techniques.

\section{Materials and Methods}

\subsection{Design Concept and Criteria}

Figure 3 presents the design concept of the control of the induction motor using wireless technology.

From Figure 3, 415 V, $50 \mathrm{~Hz}$ power supply will be available to the receiver, then onwards to the three-phase induction motor. However, the power supply will flow from a socket outlet to the receiver, then to the three-phase induction motor when the transmitter is switched on.

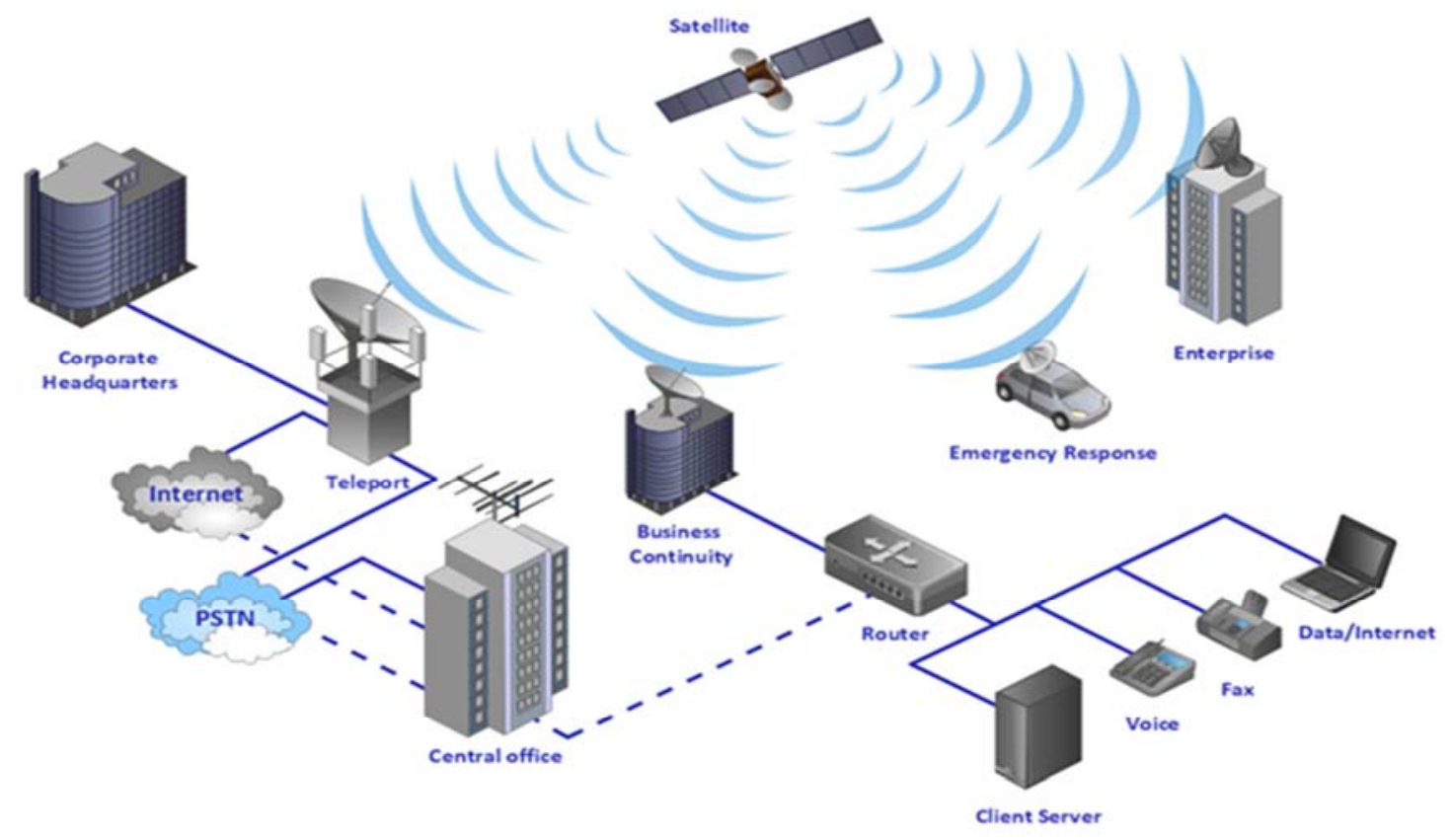

Figure 2. Satellite Networks.

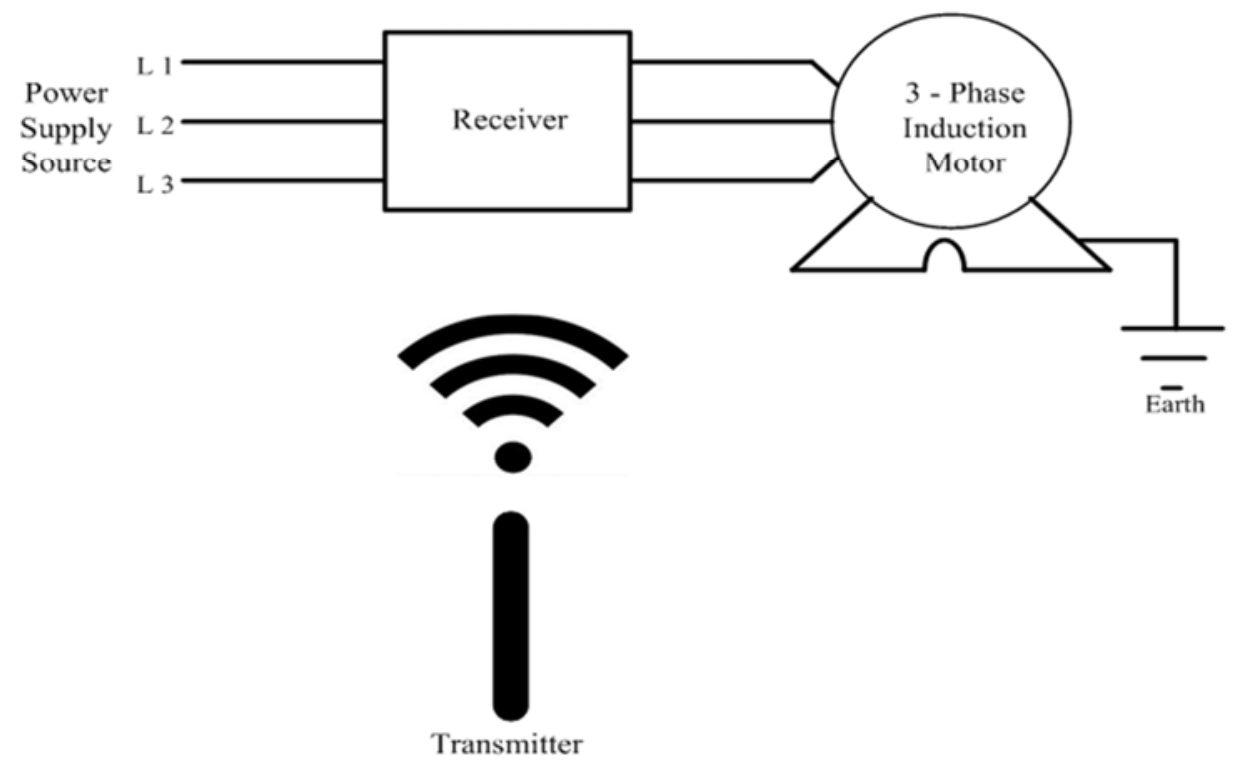

Figure 3. Conceptual Diagram of the Proposed Design. 
The design criteria to control the induction using wireless technology are stated as follows: the

1) transmitter is powered by a $3 \mathrm{~V}$ lithium cell CR 2025 battery;

2) transmitter must generate infrared signals from a $3 \mathrm{~V}$ battery power source;

3) transmission of the signals from the transmitter to the receiver is wireless;

4) system must control three-phase, 415 volts, 50 hertz squirrel cage induction motor;

5) system must be efficient and less power consuming compared to wired controls; and

6) transceiver must function in real-time with reduced number of wires.

\subsection{The Proposed Design}

Figure 4 (a) shows the functional block diagram of the transmitter. It comprises of a $3 \mathrm{~V}$ dc power source, transmitter circuit, and output signals. The transmitter converts the $3 \mathrm{~V}$ power supply to infrared signal, then transmits the signal through free space to the receiver.

Figure 4 (b) presents the functional block diagram of the receiver. It comprises of $415 \mathrm{~V}, 50 \mathrm{~Hz}$ ac source, receiver circuit, indicator lights, and a three-phase induction motor. The power is supplied to the receiver circuit. Infrared signals from the transmitter switch the receiver circuit on to allow the $415 \mathrm{~V}, 50 \mathrm{~Hz}$ ac power to flow to the indicator lights, and the three-phase induction motor.

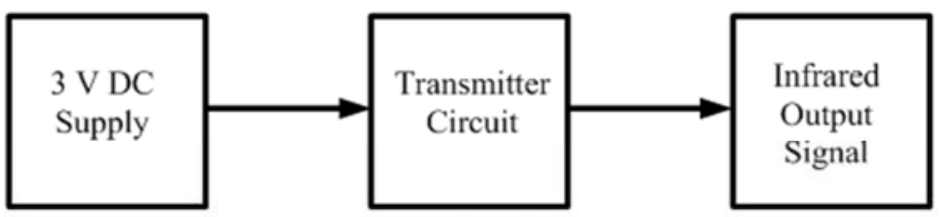

(a)

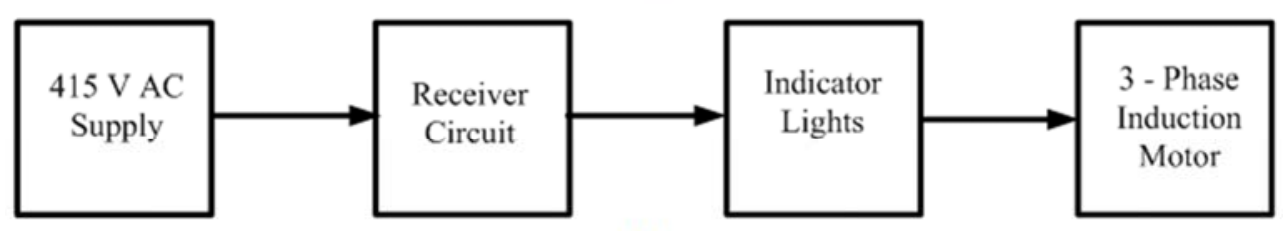

(b)

Figure 4. (a) Transmitter Block Diagram; and (b) Receiver Block Diagram.

\subsection{Selection of Components}

Selection of all the components used for the design and construction of the system are based on previous knowledge about them. Likewise, specifications and functionalities are also a major consideration in the selection of the components. The values of resistors, $\mathrm{R}$ in ohms, used for the design is given as Equation 1:

$$
\mathrm{R}=\frac{\mathrm{V}}{\mathrm{I}}
$$

where $\mathrm{V}=$ supplied voltage, volts; and

$\mathrm{I}=$ supplied current, amperes.

Likewise, the selection of NPN transistors used in the construction of the transceiver were based on Equation (2), that is:

$$
\mathrm{IB}_{\mathrm{B}}=\frac{\mathrm{V}_{\mathrm{B}}-\mathrm{V}_{\mathrm{BE}}}{\mathrm{R}_{\mathrm{B}}}
$$

where $\mathrm{I}_{\mathrm{B}}=$ base current, amperes;

$\mathrm{V}_{\mathrm{B}}=$ base voltage, volts;

$\mathrm{V}_{\mathrm{BE}}=$ base emitter voltage, volts; and

$\mathrm{R}_{\mathrm{B}}=$ base input resistance, ohms.

Also, the ratings of the transformers in the receiving circuit are calculated using Equation 3:

$$
\frac{E s}{E P}=\frac{N_{s}}{N_{P}}
$$

where $\mathrm{E}_{\mathrm{S}}=$ voltage induced in the secondary winding, volts;

$\mathrm{N}_{\mathrm{S}}=$ number of turns of the secondary windings;

$\mathrm{E}_{\mathrm{P}}=$ voltage applied to the primary winding, volts; and

$\mathrm{N}_{\mathrm{P}}=$ number of turns of the primary windings.

Similarly, the ratings of the capacitors, $\mathrm{C}$ in Farads, used for the system are calculated using:

$$
\mathrm{C}=\frac{\varepsilon \mathrm{A}}{\mathrm{d}}
$$

where $\varepsilon=$ permittivity of the dielectric;

$\mathrm{A}=$ area of the parallel plates, meters; and

$\mathrm{d}=$ distance between the plates, meters.

\subsubsection{Hardware Components of the Transmitter}

Table 1 presents the hardware components of the transmitter. The hardware components used for the construction of the transmitter circuit included NPN transistor, resistors, a $3 \mathrm{~V}$ lithium cell CR 2025, LED, micro tact switch and Vero boards. 
Table 1. List of Hardware Components of the Transmitter.

\begin{tabular}{lllll}
\hline SN & Component & Specification & Quantity & Functionality \\
\hline 1. & NPN Transistors & TIP31C & 3 & For switching and amplification of voltage to the light emitter diodes \\
2. & Resistors & $1 \mathrm{k} \Omega, 330 \Omega$ & 1 each & To reduce voltages to the base of the transistor and the light emitter diode \\
3. & Battery & $3 \mathrm{~V}$ lithium cell CR 2025 & 1 & For powering of the transmitter \\
4. & LED & $3 \mathrm{~V}$ & 1 & To convert 3 V dc source to infrared signal \\
5. & Micro Tact Switch & 0643 Model & 1 & For switching of the transmitter circuit \\
6. & Vero Boards & $160 \mathrm{~mm} \times 100 \mathrm{~mm}$ & 1 & All the components were soldered onto the Vero boards \\
\hline
\end{tabular}

\subsubsection{Hardware Components of the Receiver}

The hardware components used for the construction of the receiver circuit included step-down transformers, diodes, capacitors, transistors, electromechanical relays, colour LEDs, auto-transformers, resistors, integrated circuits, voltage regulators, a phototransistor, a fuse, an on-off switch, and Vero boards.

\subsubsection{Software Employed}

Livewire 1.11 Professional Edition software was used for the simulation of the transmitter, and the receiver circuits.

\subsubsection{Construction and Testing of the Transmitter Circuit}

Figure 5 presents the schematic diagram of the transmitter. In testing the transmitter, the micro tact switch was operated to allow current to flow from the supply through the $1 \mathrm{k} \Omega$ resistor to the base of the transistor, to enable the collector to conduct current to the LED. The LED converts the current flowing through it, into the infrared light signal, which can be propagated by the transmitter.

\subsubsection{Construction and Testing of the Receiver Circuit}

Figure 6 presents the schematic diagram of the receiver. During the testing of the receiver, infrared light signal from the transmitter was sensed by the phototransistor on the receiver. The phototransistor converted the infrared signal back to electrical signal and amplifies it. The NE 555 timer in the receiver circuit was configured as a monostable circuit to generate square waves (output pulses) to activate the CD 4017 to start its sequential switching mode by switching from speed one to speed three. The CD 4017 was designed for sequential switching from speed one, speed two up to speed three and then to an off state before the process can be re-started.

The monostable multivibrator only returns to its original stable state after a period of time determined by the time constant of the coupled circuit (R2 and C6). The CD 4017 received signals from the pin three of the NE 555 timer to its pin fourteen whenever the transmitter is activated. The output of the CD 4017 is dc which was amplified by transistors, Q2, Q3 and Q4 in order to activate relays one to three to switch on the three $24 \mathrm{~V} \mathrm{dc}$ relays to control the ac flowing through the motor to regulate the speed with three auto-transformers. LED 1, LED 2, LED 3, LED 4 and LED 5 are used for indicating purposes.

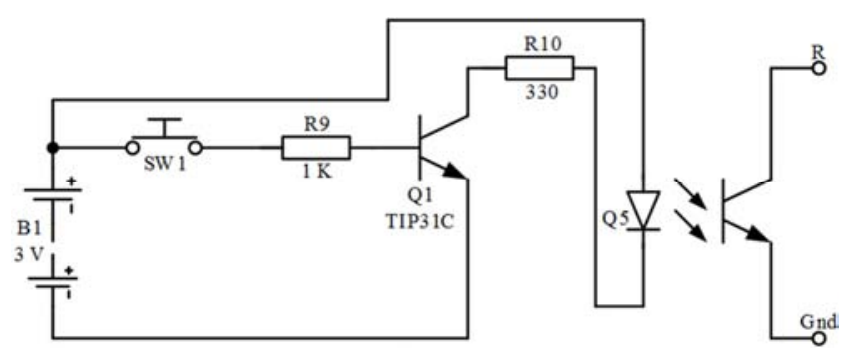

Figure 5. Schematic Diagram of the Transmitter.

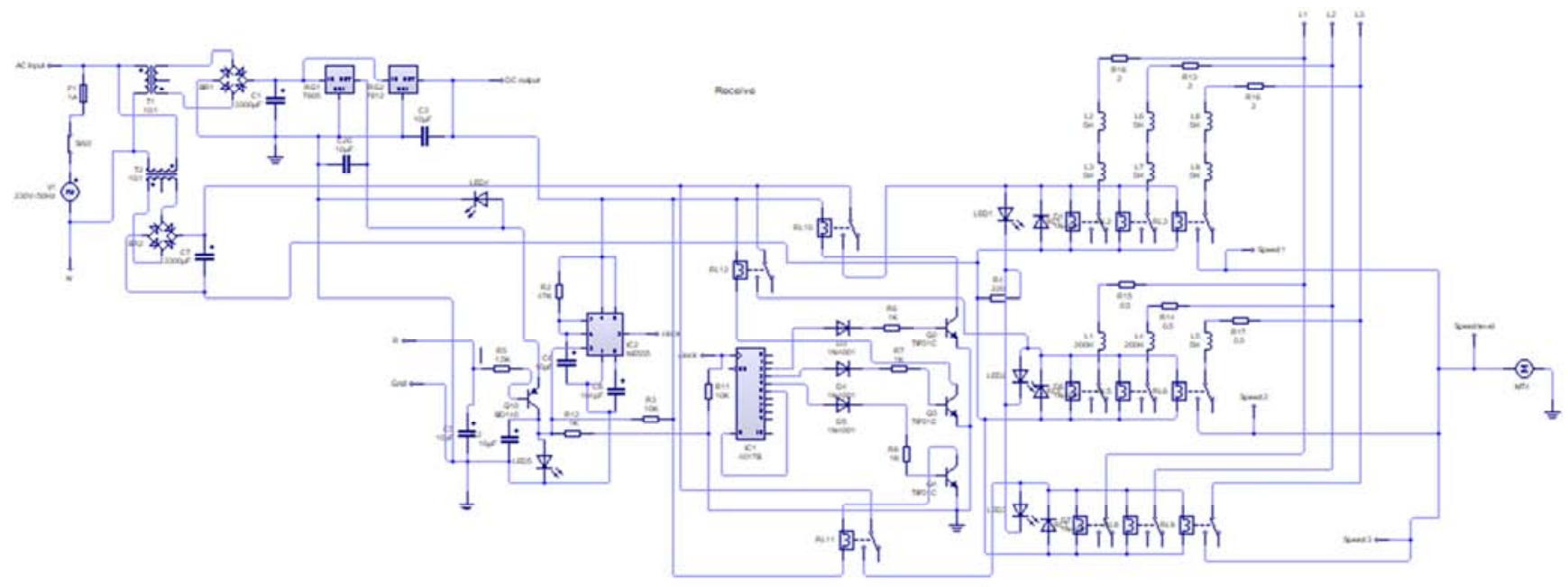

Figure 6. Schematic Diagram of the Receiver. 


\section{Results and Discussions}

\subsection{Results}

\subsubsection{Test Results of the Transceiver}

Figure 7 presents the setup of the transceiver system for testing at the laboratory. The setup consists of a 3-ph, $415 \mathrm{~V}$, $50 \mathrm{~Hz}$ power supply, a digital oscilloscope, the receiver system, the transmitter system and a $3-\mathrm{ph}, 415 \mathrm{~V}, 50 \mathrm{~Hz}$ squirrel-cage induction motor.

\subsubsection{Simulation Waveform Results of the Transceiver}

Figure 8 depicts the simulated waveforms of dc power flowing through the circuit to activate the electromagnetic relays using the Livewire 1.11 Professional Edition for the 3 speed levels. The dc voltage, $\mathrm{V}$, flowing through the electromagnetic relays is plotted against time in seconds to represent all the 3 speed levels.

\subsubsection{Output AC Waveform Results of the Transceiver}

The setup consists of a digital oscilloscope, the transmitter system, and the receiver system. Experiments were conducted on the transceiver system to measure the output ac waveforms of its corresponding speed levels connected to the squirrel-cage induction motor.

The various speeds i.e., first, second and third; are presented in Figures 9 (a), (b) and (c) with the experimental setup of the transceiver system at the laboratory for the three speed levels. The amber, green and blue LEDs represent the first, second and third speed levels which lights-up when the signal from the transmitter are sensed by the receiver.

\subsubsection{Output Voltage and Current Results of the Transceiver}

The setup consists of the transmitter system, the receiver system, and five digital multimeters. Two digital multimeters were used to measure the output line voltage values, and the other three digital multimeters were used to measure the output line current values of the corresponding speed levels. Table 2 depicts the recorded values of the output line voltages and Table 3, the output line current of the squirrel-cage induction motor under no-load condition.

\subsubsection{Measured Results of Speed Levels of the Transceiver}

The setup consists of the transmitter system, the receiver system, and a photo-tachometer. This test was conducted on the transceiver system to measure the actual speed levels of the $1500 \mathrm{rpm}$ motor. Table 4 presents the recorded maximum values of the three speed levels.

\subsubsection{Temperature Versus Time Results of the Transceiver}

The setup consists of the transmitter system, the receiver system, Type-K thermocouple and thermometer. This test was conducted on the transceiver system to measure the temperature rise of the transmitter against time with the receiver connected to the motor under no-load condition at the third speed level. Table 5 shows the recorded values of the temperature and time.

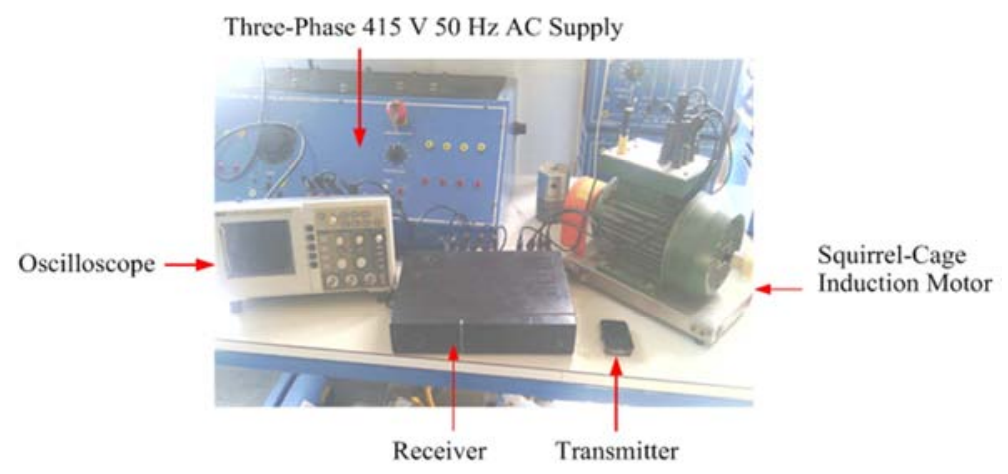

Figure 7. Setup for Testing the Transceiver System.

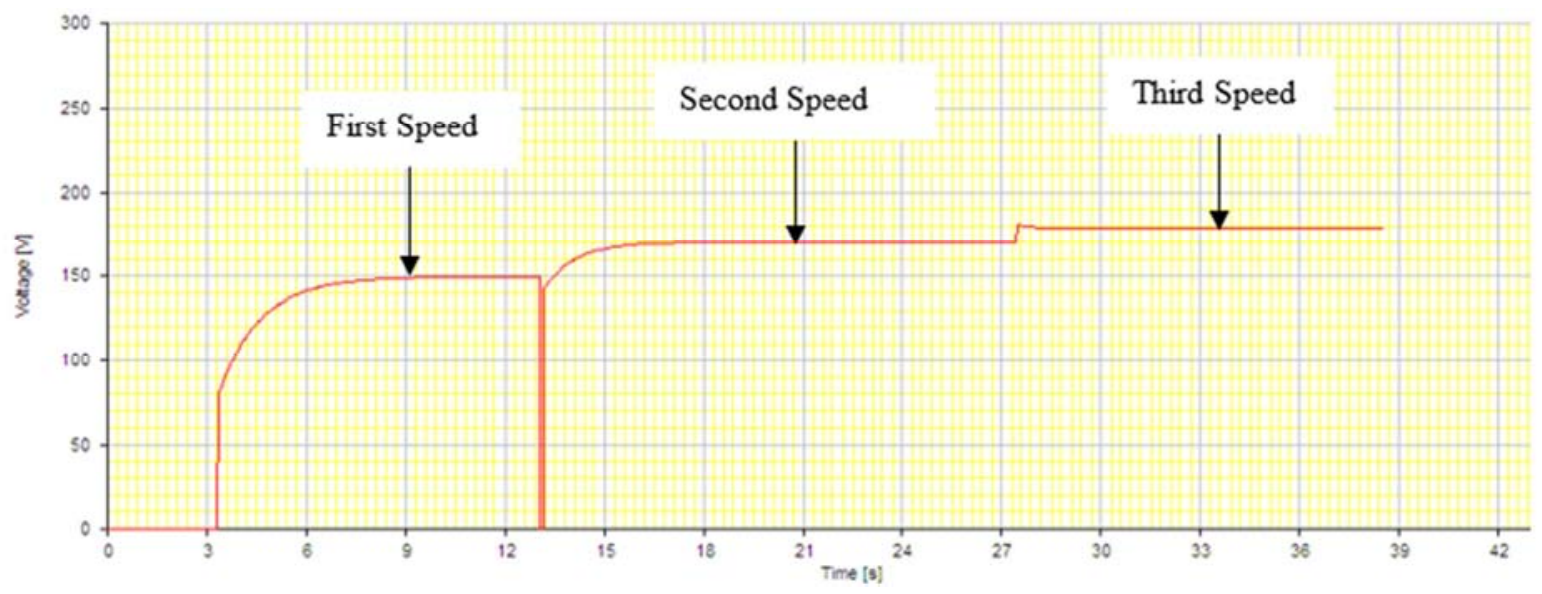

Figure 8. Simulated Waveforms of the Three Speed Levels. 


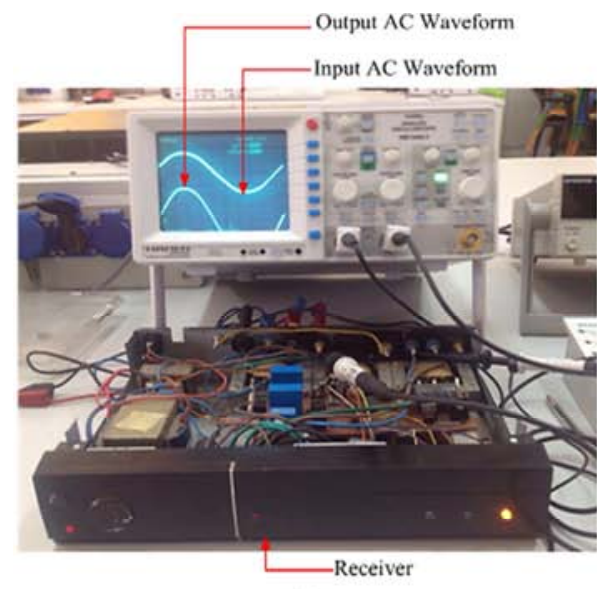

(a)

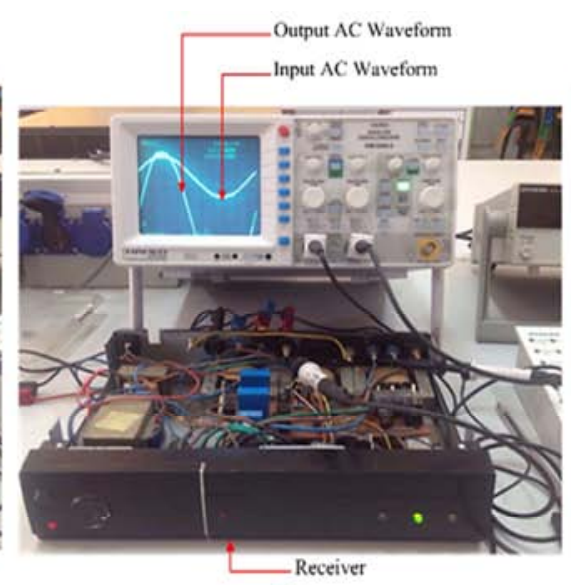

(b)

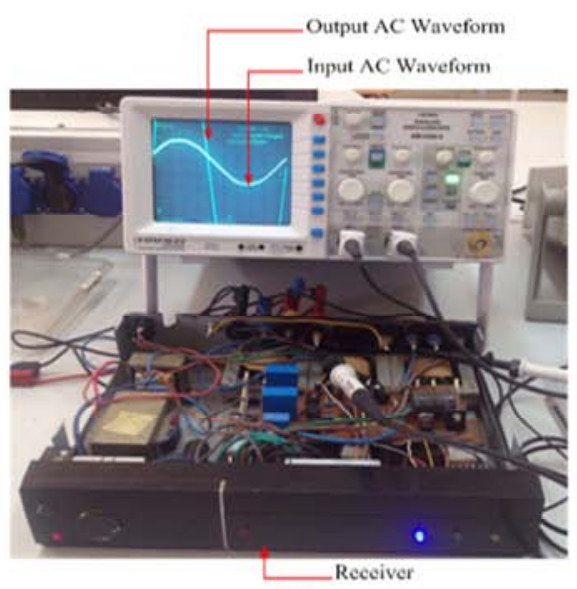

(c)

Figure 9. (a) Output AC Waveform of the First Speed; (b) Output AC Waveform of the Second Speed; and (c) Output AC Waveform of the Third Speed.

Table 2. Output Line Voltage Values of the Motor Under No-load Condition.

\begin{tabular}{llll}
\hline Speed Levels & $\mathbf{1}^{\text {st }}$ & $\mathbf{2}^{\text {nd }}$ & $\mathbf{3}^{\text {rd }}$ \\
\hline Voltage (V) & 212 & 242 & 394 \\
\hline & & Table 3. Output Line Current Values of the Motor Under No-load Condition. \\
\hline Speed Levels & $\mathbf{1}^{\text {st }}$ & $\mathbf{2}^{\text {nd }}$ & $\mathbf{3}^{\text {rd }}$ \\
\hline Current (A) & 0.94 & 1.07 & 1.85 \\
\hline
\end{tabular}

Table 4. Measured Values of Speed Levels.

\begin{tabular}{llll}
\hline Speed Levels & $\mathbf{1}^{\text {st }}$ & $\mathbf{2}^{\text {nd }}$ & $\mathbf{3}^{\text {rd }}$ \\
\hline Measured Speed (rpm) & 1472 & 1474 & 1478 \\
\hline
\end{tabular}

Table 5. Recorded Temperature and Time Values.

\begin{tabular}{lllllllllllll}
\hline Temperature $\left({ }^{\circ} \mathbf{C}\right)$ & $\mathbf{3 1}$ & $\mathbf{3 3}$ & $\mathbf{3 6}$ & $\mathbf{3 8}$ & $\mathbf{4 0}$ & $\mathbf{4 3}$ & $\mathbf{4 5}$ & $\mathbf{4 6}$ & $\mathbf{4 8}$ & $\mathbf{4 8}$ & $\mathbf{4 8}$ & $\mathbf{4 8}$ \\
\hline Time (minutes) & 5 & 10 & 15 & 20 & 25 & 30 & 35 & 40 & 45 & 50 & 55 & 60 \\
\hline
\end{tabular}

\subsection{Discussions}

\subsubsection{Discussion of the Test Results of the Transceiver}

Figure 7 depicts the setup of the transceiver for this test. Initially, the timer NE 555 circuit, was not included and the system was tested. It was observed that, the counter circuit did not work perfectly due to interferences from the phototransistor circuitry because the output of the phototransistor was connected directly to the $14^{\text {th }}$ pin on the counter. The micro tact switch on the transmitter bounced, whenever it was pressed to activate the system. This generated multiple signals to the counter circuit to make it work abnormally. Additionally, the configuration of the counter circuit was causing the transistors, Q2, Q3 and Q4 to burn out. This was due to the low resistive values at the bases of the transistors that did not drop enough current flowing to the bases of the transistors.

The timer NE 555 circuit was introduced into the system to reduce the bouncing effects and restore the counter circuit. Also, an electrolytic capacitor was introduced to eliminate the interferences from the phototransistor circuit. This allowed the timer NE 555 circuit to hold up the pulses at the $14^{\text {th }}$ pin of the counter for the system to function well. Further, the resistance values at the bases of transistors, Q2, $\mathrm{Q} 3$, and $\mathrm{Q} 4$, were increased to drop enough voltage to protect the bases of the transistors from burning out. The effective range within which the transmitter signal is sensed by the receiver is $9 \mathrm{~m}$.

\subsubsection{Discussion of the Simulation Waveform Results of the Transceiver}

Figure 8 illustrates the simulated waveforms of the three speed levels. The first activation of the micro tact switch sent infrared signal from the transmitter to the receiver to put the receiver in standby mode with red indicating LED on. At this instance, the motor was at a standstill and no voltage was flowing to the motor. When the micro tact switch was activated for the second time, the input voltage to the motor increased suddenly from $0 \mathrm{~V}$ to $80 \mathrm{~V}$. This was the initial inrush current at the start of the induction motor.

The voltage continued to increase to $150 \mathrm{~V}$. This voltage was maintained for the first speed level. When the micro tact switch was activated for the third time, a signal was sent from the transmitter to the receiver. The voltage reduced suddenly from $150 \mathrm{~V}$ to $0 \mathrm{~V}$ and then increased again from $0 \mathrm{~V}$ to $140 \mathrm{~V}$. The voltage further increased to $170 \mathrm{~V}$ indicating the second speed level. This voltage was maintained for the second speed. For the third speed level, the micro tact switch was activated for the fourth time to send signal from the transmitter to the receiver. The voltage suddenly increased from $170 \mathrm{~V}$ to $182 \mathrm{~V}$. 
Then voltage reduced from $182 \mathrm{~V}$ to $180 \mathrm{~V}$. This was because there was enough magnetic flux in the system. This voltage was maintained for the third speed level.

\subsubsection{Discussion of the Output AC Waveform Results of the Transceiver}

Figure 9 (a), (b), and (c) presents an oscilloscope display of the ac output waveform of the first, second and third speed levels of the induction motor. In Figure 9 (a), the waveform shows that, at the first speed level, less voltage flows through the auto-transformer to the motor and results in low speed and low torque of the induction motor. In Figure 9 (b), the waveform shows that, at the second speed level, medium voltage flows through the auto-transformer to the motor, which results in moderate speed and quite a high torque of the induction motor.

Finally, in Figure 9 (c), the waveform shows that at the third speed level, the full voltage is applied through the auto-transformer to the motor, which also results in the highest speed and torque of the induction motor.

\subsubsection{Discussion of the Output Voltage and Current Results of the Transceiver}

The voltage applied to the motor at the first speed level is 212 $\mathrm{V}$ AC (Alternating Current). The voltage value increases to 242 $\mathrm{V} A \mathrm{AC}$ at the second speed level. Finally, the voltage value increases to 394 at the third speed level. The initial current intake to the motor at the first speed level is $0.94 \mathrm{~A}$, the second increases to $1.07 \mathrm{~A}$ and the third $1.85 \mathrm{~A}$. Tables 2 and 3 present the recorded output line voltage and current values for the three speed levels.

\subsubsection{Discussion of the Measured Results of Speed Levels of the Transceiver}

Table 4 presents the recorded maximum values of the three speed levels. The test is conducted to measure the actual speed level of the induction motor. The speed levels one, two and three were $1472 \mathrm{rpm}, 1474 \mathrm{rpm}$, and $1478 \mathrm{rpm}$ respectively.

\subsubsection{Discussion of the Temperature Versus Time Results of the Transceiver}

Table 5 presents the recorded temperature and time values of the transceiver system for a period of 1 hour ( 60 minutes). The initial ambient temperature was $31^{\circ} \mathrm{C}$, which remained the same for the first 5 minutes. This temperature values increased up to $48^{\circ} \mathrm{C}$ at the time of 45 minutes. The $48^{\circ} \mathrm{C}$ remained the same up to the 60 minutes of the test.

\subsection{Cost Analysis}

Table 6 presents the cost analysis of implementing the transmitter. Total amount of $\mathrm{GH} \notin 117.00$ is needed based on the item description, specification and quantity. $10 \%(\mathrm{GH} \phi$ $11.70)$ and $5 \%(\mathrm{GH} \notin 5.85)$ of the total amount are allocated for preliminaries and contingency respectively. Therefore, sum total amount of $\mathrm{GH} \phi 134.55$ is required for successful implementation of the transmitter.

Table 7 presents the cost analysis of implementing the receiver. The sum total amount of $\mathrm{GH} \not 545.68$ is required for successful implementation of the receiver.

Table 6. Cost Analysis of Implementing the Transmitter.

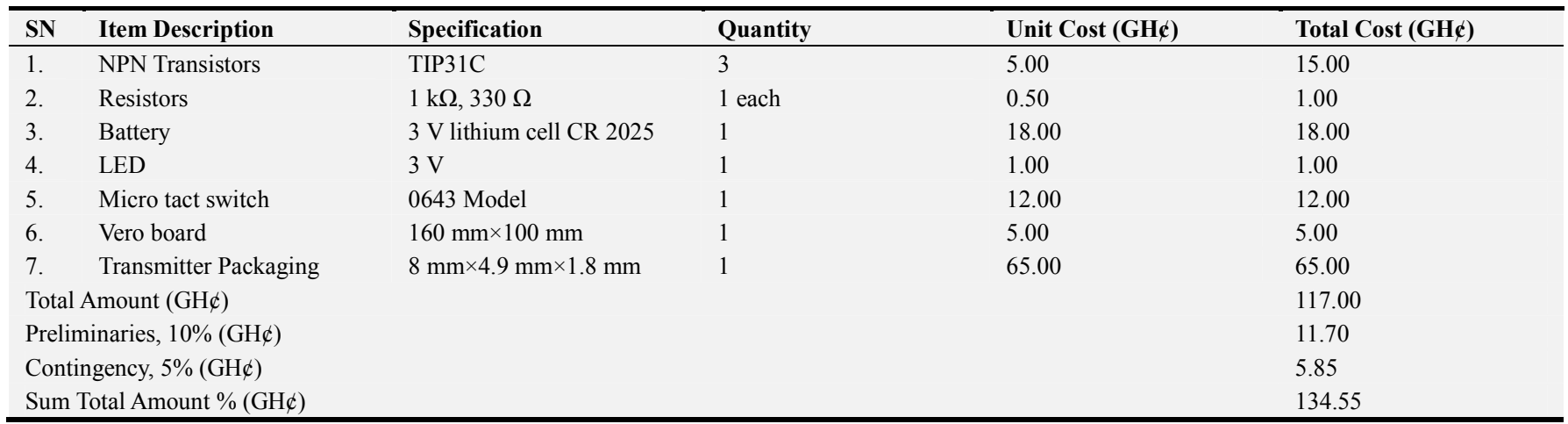

Table 7. Cost Analysis of Implementing the Receiver.

\begin{tabular}{|c|c|c|c|c|c|}
\hline SN & Item Description & Specification & Quantity & Unit Cost (GHe) & Total Cost (GHe) \\
\hline \multirow{2}{*}{1.} & \multirow{2}{*}{ Step-down Transformer } & 230/24 VAC $50 \mathrm{~Hz} 500 \mathrm{~mA}$ & 1 & 25.00 & 25.00 \\
\hline & & 230/24 VAC $50 \mathrm{~Hz} 5000 \mathrm{~mA}$ & 1 & 45.00 & 45.00 \\
\hline \multirow[t]{2}{*}{2.} & \multirow[t]{2}{*}{ Diode } & IN4002 & 19 & 1.50 & 28.50 \\
\hline & & $3300 \mu \mathrm{F} 35 \mathrm{~V}$ & 1 & 3.50 & 3.50 \\
\hline \multirow{3}{*}{3.} & \multirow{3}{*}{$\begin{array}{l}\text { Battery LED Micro tact } \\
\text { switch Vero board }\end{array}$} & $10 \mu \mathrm{F}, 50 \mathrm{~V}$, electrolytic & 4 & 2.00 & 8.00 \\
\hline & & $4700 \mu \mathrm{F}, 35 \mathrm{~V}$, electrolytic & 1 & 4.00 & 4.00 \\
\hline & & $104 \mathrm{nF}$ & 1 & 2.00 & 2.00 \\
\hline \multirow{2}{*}{4.} & \multirow{2}{*}{ Transmitter Packaging } & PNP Transistor (BD140) & 1 & 4.50 & 4.50 \\
\hline & & NPN Transistor (TIP122) & 1 & 5.00 & 5.00 \\
\hline \multirow{2}{*}{5.} & & $12 \mathrm{VDC}(\mathrm{SPCO})$ & 3 & 6.00 & 18.00 \\
\hline & & $24 \mathrm{VDC}(\mathrm{DPCO})$ & 3 & 7.00 & 21.00 \\
\hline 6. & Coloured LEDs & $3 \mathrm{~V}$ & 5 & 1.00 & 5.00 \\
\hline 7. & Auto-transformers & $415 \mathrm{AC} 50 / 60 \mathrm{~Hz}$ & 3 & 65.00 & 195.00 \\
\hline 8. & Resistors & $100 \Omega, 47 \mathrm{k} \Omega, 10 \mathrm{k} \Omega, 220 \Omega, 1.5 \Omega, 220 \Omega$ & 8 & 0.50 & 4.00 \\
\hline
\end{tabular}




\begin{tabular}{|c|c|c|c|c|c|}
\hline SN & Item Description & Specification & Quantity & Unit Cost (GHe) & Total Cost $(\mathrm{GH} \dot{c})$ \\
\hline \multirow{2}{*}{9.} & & CD4017 & 1 & 15.00 & 15.00 \\
\hline & & Timer NE555 & 1 & 5.00 & 5.00 \\
\hline \multirow{2}{*}{10.} & & LM7805 & 1 & 4.00 & 4.00 \\
\hline & & LM7812 & 1 & 4.00 & 4.00 \\
\hline 11. & Phototransistor & TSOP1356 & 1 & 45.00 & 45.00 \\
\hline 12. & Fuse & $230 \mathrm{~V} 5 \mathrm{~A}$ & 1 & 1.00 & 1.00 \\
\hline 13. & On-off Switch & $230 \mathrm{~V}$ & 1 & 2.00 & 2.00 \\
\hline 14. & Vero Boards & $160 \mathrm{~mm} \times 100 \mathrm{~mm}$ & 5 & 5.00 & 25.00 \\
\hline 15. & Receiver Packaging & $30 \mathrm{~mm} \times 21 \mathrm{~mm} \times 6.1 \mathrm{~mm}$ & 1 & 50.00 & 5.00 \\
\hline \multicolumn{3}{|c|}{ Total Amount (GHф) } & & & 474.50 \\
\hline \multicolumn{3}{|c|}{ Preliminaries, $10 \%(\mathrm{GH} \phi)$} & & & 47.45 \\
\hline \multicolumn{3}{|c|}{ Contingency, $5 \%(\mathrm{GH} \phi)$} & & & 23.73 \\
\hline \multicolumn{3}{|c|}{ Sum Total Amount $\%(\mathrm{GH} \phi)$} & & & 545.68 \\
\hline
\end{tabular}

The summation of the transmitter cost GHф 134.55 (approx. 23.20 USD) and the receiver cost GH $\varnothing 445.68$ (approx. 94.08 USD) yield GH $\varnothing 680.23$. Therefore, the total cost for the construction of the transceiver system is $\mathrm{GH} \notin 680.23$ (approx. 117.28 USD).

\subsection{Summary of Findings}

Findings from this research are summerised as follows:

1) Wireless technology can be employed to control three-phase squirrel-cage induction motor at different locations, without the need for modification of the control wiring scheme;

2) The effective sensing range of the receiver system from the transmitter is $9 \mathrm{~m}$;

3) The control system reduces the initial current with respect to the different speed levels before applying the full rated voltage to the motor at the final speed;

4) The various speed levels must be attained before the system can be stopped; and

5) The control system follows the line-of-sight principle for effective operation.

\section{Conclusions}

The control of a 3-ph, $415 \mathrm{~V}, 50 \mathrm{~Hz}$, squirrel-cage induction motor via wireless medium using infrared signal was achieved. Equally, slips, trips and falls dangers associated with the tracing of motor control wires during troubleshooting were reduced.

More significantly, the research has shown that:

1) Infrared wireless transmission technology is applicable to the control of three-phase, $415 \mathrm{~V}, 50 \mathrm{~Hz}$, squirrel-cage induction motor;

2) There are different types of wireless technologies available that can be implemented in motor control systems; and

3) Wireless control systems are more reliable as compared to wired control systems because of reduction of control wires that are prone to breakages when objects fall on those wires.

\section{Recommendations}

Based on the successful undertaking of the research, the following recommendations are made:
1) The 3 V lithium cell CR 2025 in the transmitter must be changed every five years as per the manufacturer's recommendation;

2) The $3 \mathrm{~V}$ lithium cell CR 2025 in the transmitter must be removed and stored in a place free from moisture and sunlight when the system is not in use for at least a week;

3) The designed transceiver system must be used for controlling only a $3-\mathrm{ph}, 415 \mathrm{~V}, 50 \mathrm{~Hz}$, squirrel-cage induction motors;

4) Future work can look into the ability to stop the system within the different speed level before stopping the system; and

5) Likewise, further research can be conducted on this research to overcome the line-of-sight challenge of infrared wireless transmission technology and the deployment of this system in the control of wound rotor motors.

\section{References}

[1] Hossein-Ali, K. (2015), "Dynamic Analysis of Three-Phase Induction Motor in Dig Silent Power Factory", MSc Thesis, School of Engineering and Information Technology, Murdoch University, Perth, Australia, pp. 67-77.

[2] Anon. (2012), "Manual Motor Control and Overload Protection", Electric Motor Control Learning Activity Packet 2, Amatrol Incorporated, Jeffersonville, USA, pp. 6-7.

[3] Anon. (2013a), "Motor Control Solutions", Data Bulletin, Schneider Electric, Knightdale, New York City, USA, pp. 11-15.

[4] Anon. (2013b), "Scalar (V/F) Control of Three-Phase Induction Motors", Application Report, Texas Instruments, Dallas, Texas, USA, pp. 3-5.

[5] Kailaswar, S. V. and Keswani, R. A. (2013), "Speed Control of Three-Phase Induction Motor by V/F Method for Batching Motion System", International Journal of Engineering Research and Applications, Vol. 3, No. 2, pp. 1732-1736.

[6] Sarhan, H. (2014), "Effect of High-Order Harmonics on Efficiency-Optimized Three-Phase Induction Motor Drive System Performance", International Journal of Enhanced Research in Science Technology and Engineering, Vol. 3, No. 4, pp. 15-20.

[7] Thinga, R., Gupta, S. and Phulambikar, S. P. (2014), "Field Oriented Control of Single-Phase Induction Motor", International Journal of Emerging Technology and Advanced Engineering, Vol. 4, No. 8, pp. 760-763. 
[8] Anon. (2015a), "Grundfos Motor Book", www.grundfos.com. Accessed: January 13, 2016.

[9] Karim, K. A., Yusoff, N. A. M., Jidin, A., Patkar, F., Firdaus, R. N. and Jamil, M. (2015), "Analysis of Five-Phase Induction Motor with Dynamic Load", Asian Research Publishing Network Journal of Engineering and Applied Sciences, Vol. 10, No. 20, pp. $9830-9834$.

[10] Anon. (2016a), "Wireless Communications", www.techopedia.com/definition/10062/ wireless-communications. Accessed: February 10, 2016.

[11] Anon. (2016b), "History of Wireless Communications", www.microwavejournal.com/ articles/24759. Accessed: February 10, 2016.

[12] Jilani, S. A. (2015), "Spectrum Allocation Methods Studying Allocation through Auctions", Journal of Economics, Business and Management, Vol. 3, No. 7, pp. 742-745.

[13] Anon. (2016c), "Spectrum Allocation in Ghana", www.nca.org.gh. Accessed: February 11, 2016.

[14] Deliversky, J., Yaneva-Deliverska, M., Lyapina, M. and Kisselova, A. (2015), "European and International Standards on Medical Devices for Dentistry", International Medical Association of Bulgaria, Vol. 21. No. 1, pp. 713-717.

[15] Anon. (2013c), "Empowering the Evolution of Technology", Annual Report, New York, USA, pp. 13-14.

[16] Anon. (2014), "Encouraging the Next Generation of Standards Expects", World Standards Co-operation Day, Ottawa, Canada, pp. 6-7.

[17] Anon. (2013d), "Performances and Feasibility of mmWave Beam Forming Prototype for 5G Cellular Communications", Communications Research Team, Samsung Electronics Corporation, pp. 1-29.

[18] Azar, Y., Wong, G. N., Wang, K., Mayzus, R., Schulz, J. K., Zhao, H., Gutierrez, F. Jr., Hwang, D. D. and Rappaport, T. S. (2013), "28 GHz Propagation Measurements for Outdoor Cellular Communications Using Steerable Beam Antennas", IEEE International Conference on Communications, New York City, USA, pp. 1-2.

[19] Walter, L. O. and Kritzinger, P. S. (2016), "Cellular Networks Past, Present and Future" www.faculty.kfupm.edu.sa/ICS/salah/082/ics343/handouts/mo bile/mobileO. Accessed: February 15, 2016.

[20] Banerji, S. (2013), "Upcoming Standards in Wireless Local Area Networks", Wireless and Mobile Technologies, Vol. 1, No. 1, pp. 1-2.

[21] Anon. (2016d), "Roaming Wireless Local Area Network Diagram", www.conceptdraw.com/examples/local-areanetwork-diagram. Accessed: February 15, 2016.

[22] Nathaniel, S., Onwuka, E. N., Adegboyega, A. J. and Suleiman, D. U. (2013), "Networks Integration between Wireless LAN and UMTS Networks", Journal of Emerging Trends in Computing and Information Sciences, Vol. 4, No. 5, pp. 459-465.

[23] Vadde, A. R. and Bokka, R. (2015), "Integration of Access Technology of Wireless World Wide Web", Global Journal of Engineering Science and Research Management, Vol. 2, No. 3, pp. 24-30.
[24] Anon. (2016e), "Wireless Installation", www.innetrex.com/ wireless_install.php. Accessed: February 16, 2016.

[25] Alsamhi, S. H. (2015), "An Intelligent HAP for Broadband Wireless Communications: Developments, QoS and Applications", International Journal of Electronics and Electrical Engineering, Vol. 3, No. 2, pp. 134-143.

[26] Madhow, U. (2014), Introduction to Communication Systems, University of California, Santa Barbara, USA, pp. 41-42.

[27] Anon. (2016f), "Ad Hoc Wireless Network Diagram", www.conceptdraw.com/examples/wireless-wlan. Accessed: February 15, 2016.

[28] Fagiri, M. A. O. and Nerma, M. H. M. (2015), "Sequential Paging Technique in the Fourth Generation Communication System", GE-International Journal of Engineering Research, Vol. 3, No. 4, pp. 64-75.

[29] Anon. (2016g), "Wireless Paging Systems and Urgent Communication Solutions", www.visiplex.com/products /onsite-paging.html. Accessed: 17, February, 2016.

[30] Anon. (2016h), "Using Both Wired and Wireless Connections", www.conceptdraw.com/How-To-Guide/using-both-wiredand-wireless connections. Accessed: February 15, 2016.

[31] Vishnudas, C. S. and Sreehari, S. (2015), "Multilevel Inverter Based VFD for Three- Phase Induction Motor", International Research Journal of Engineering and Technology, Vol. 2, No. 5, pp. 274-278.

[32] Preethi, K., Anil, G. and Vani, E. (2013), "Speed Control of Induction Motor Using Eleven Levels of Multilevel Inverter", International Journal of Science and Modern Engineering, Vol. 1, No. 5, pp. 15-20.

[33] Snehasish, P., Santanu, N. and Debajyoti, P. (2015), "Adjustable Speed Control of Induction Motor using Variable Frequency Drives", GE-International Journal of Engineering Research, Vol. 3, No. 4, pp. 13-24.

[34] Madivalappa, B. and Aspalli, M. S. (2013), "Speed Control of Three-Phase Induction Motor by Variable Frequency Drive", International Journal of Advanced Research in Computer Science and Software Engineering, Vol. 3, No. 12, pp. 411-412.

[35] Zaini, H. G., Metwally, M. K. and Ahmed, M. (2014), "Direct Torque Control of Induction Motor Drive Fed from Hybrid Multilevel Inverter", International Journal of Electrical and Computer Sciences, Vol. 14, No. 3, pp. 6-11.

[36] Petrovic, I., Jozsa, L. and Baus, Z. (2015), "Use of Fuzzy Logic Systems for Assessment of Primary Faults", Journal of Electrical Engineering, Vol. 66, No. 5, pp. 257-263.

[37] Husna, V. A. and Kumar, N. M. (2014), "Performance Analysis of Sensorless Based DTC of Induction Motor using Neuro-Fuzzy", International Journal of Advanced Research in Electrical, Electronics and Instrumentation Engineering, Vol. 3, No. 2, pp. 602-609.

[38] Sethu, P., Selvaraj, A. and Surendar, S. (2014), "A Wireless Speed Control of AC Drive System", International Journal of Advanced Research in Electrical, Electronics and Instrumentation Engineering, Vol. 3, No. 2, pp. 448-456. 